\title{
Development of immunochromatographic device as a point-of-care tool for serodiagnosis of human strongyloidiasis cases
}

\author{
Lakkhana Sadaow $^{1,2} \cdot$ Oranuch Sanpool ${ }^{1,2} \cdot$ Rutchanee Rodpai $^{1,2} \cdot$ Patcharaporn Boonroumkaew ${ }^{1,2}$. \\ Wanchai Maleewong ${ }^{1,2}$. Pewpan M. Intapan ${ }^{1,2}$ (D)
}

Received: 24 August 2019 / Accepted: 21 October 2019 / Published online: 22 November 2019

(C) The Author(s) 2019

\begin{abstract}
Human strongyloidiasis is an important gastrointestinal disease with an estimated 30 to 100 million people infected. Prevalence is generally underestimated since many infections are asymptomatic, and traditional diagnostic tests based on parasitological examination of stool samples are not adequately sensitive. Serological tests are useful and supportive but are still only available in a reference research setting. We made an immunochromatographic test (ICT) kit for rapid serodiagnosis of human strongyloidiasis. The antigen used in the ICT kit was extracted from larvae of Strongyloides stercoralis. Diagnostic efficacy of the kit was evaluated using human serum samples from strongyloidiasis patients, healthy persons, and those with other parasitoses. When using a cutoff level of 0.5 or above, the diagnostic sensitivity, specificity, and positive and negative predictive values at the prevalence of infection of $34.4 \%$, were $93.3 \%, 83.7 \%, 76.7 \%$, and $95.6 \%$, respectively. This ICT kit is easy to use at the point-ofcare and a result can be obtained in $15 \mathrm{~min}$. Sophisticated instruments and highly trained staff are not required. It can be used in several diagnostic and public-health settings, e.g., prevalence surveys in endemic areas, confirmation and monitoring of cure post-treatment, diagnosis and screening of infected but asymptomatic individuals, and populations "at risk" for hyperinfection syndrome or disseminated strongyloidiasis if they are given immunosuppressive treatment for other conditions.
\end{abstract}

Keywords Diagnosis $\cdot$ Immunochromatographic test $\cdot$ Screening test $\cdot$ Rapid test $\cdot$ Strongyloidiasis $\cdot$ Strongyloides stercoralis

\section{Introduction}

Human strongyloidiasis, a soil-transmitted helminthiasis, is a harmful intestinal parasitic disease that is distributed globally and infects an estimated 30 to 100 million people [1-4]. Strongyloides stercoralis is the main causative agent, while Strongyloides fulleborni has been reported from people in some parts of Africa, Papua New Guinea, and Thailand [1, 5]. The true number of infections is likely underestimated due to the low sensitivity of diagnostic tools delays in diagnosis. Three factors lead to delayed diagnosis: subclinical cases

Pewpan M. Intapan

pewpan@kku.ac.th

1 Department of Parasitology and Excellence in Medical Innovation, and Technology Research Group, Faculty of Medicine, Khon Kaen University, Khon Kaen, Thailand

2 Research and Diagnostic Center for Emerging Infectious Diseases, Mekong Health Science Research Institute, Khon Kaen University, Khon Kaen, Thailand which remain unsuspected and undetected, irregular larval output in the feces making diagnosis difficult, and the lack of a gold-standard diagnostic test $[4,6]$.

The disease is generally diagnosed by detecting parasites in stool samples using methods such as direct fecal smear examination, Baermann concentration, formalin-ethyl acetate concentration, Harada-Mori filter paper culture, and agar plate cultures $[4,7]$. However, these methods are complicated, require skilled microscopists, and are time-consuming. Furthermore, intermittent releases of worms in feces dictate the need for multiple stool examinations [8]. Molecular techniques such as polymerase chain reaction (PCR) and real-time PCR, for the detection of Strongyloides DNA in stool or urine samples, have been reported [9-14]. Serological assays (to detect antibody or antigen) can be used to provide support for a diagnosis [15-17]. For example, immunoblotting has been used to detect specific antibody against various antigenic polypeptide bands [18-24]. Recently, Yunus et al. [25] reported the developed lateral flow dipstick test using recombinant protein antigens for detection of human IgG4 antibody has been reported and the results showed high diagnostic 
sensitivity and specificity. However, these methods are also time consuming and require specialized equipment not generally available at the point-of-care (POC), and some methods require sophisticated and expensive instruments only found in advanced laboratories.

Here, we describe a new strip device, the rapid diagnostic immunochromatographic test (ICT) using somatic S. stercoralis larval soluble extract antigen for detection IgG antibodies in human sera. This POC test is simple and can be performed at the bedside for serodiagnosis of human strongyloidiasis.

\section{Materials and methods}

\section{Parasites and antigens}

Strongyloides stercoralis third-stage larvae were obtained from fecal samples from infected patients using the filter paper culture technique [26]. Larvae were washed several times in distilled water and then stored at $-20{ }^{\circ} \mathrm{C}$ until use. The frozen sample, packed with $S$. stercoralis L3 $(500 \mu \mathrm{L})$, was homogenized with a tissue grinder in a small volume of distilled water containing $0.1 \mathrm{mM}$ phenylmethylsulfonyl fluoride and $0.1 \mu \mathrm{M} \mathrm{N}$-( $N$-[L-3 trans-carboxyoxiran-2-carbonyl]-Lleucyl)-agmatine. The extraction was then sonicated with an ultrasonic disintegrator and centrifuged at $10,000 \times \mathrm{g}$ for $30 \mathrm{~min}$ at $4{ }^{\circ} \mathrm{C}$. The supernatant was assayed for protein concentration using the Quick Start Bradford Protein Assay (Bio-Rad Laboratories Inc., CA). The somatic larval soluble extract was kept as the source of antigen and stored at $-70{ }^{\circ} \mathrm{C}$ until used.

\section{Human sera}

Human serum samples were used for evaluation of the diagnostic value of the test. These sera were supplied by the frozen sample bank $\left(-70^{\circ} \mathrm{C}\right)$ at the Faculty of Medicine, Khon Kaen University. The samples were divided into three groups: (i) the negative control group $(n=30)$ comprised samples from healthy adult volunteers who were free (based on stool examination) [27] from any intestinal parasitic infection at the time of blood collection; (ii) the strongyloidiasis group $(n=60)$, which comprised samples from parasitologically confirmed strongyloidiasis patients (based on the agar-plate culture method) [28], and (iii) serum samples $(n=74)$ from patients with parasitic infections other than strongyloidiasis (Table 1). The infections were verified by parasitological methods, except in cases of cysticercosis which were diagnosed using a computerized tomography scan and an immunological method [29] (Table 1). Pooled serum samples from the healthy individuals and from strongyloidiasis patients were also used as negative and positive controls, respectively. Precision of the method was investigated by performing the test on the same samples on different days: no day-to-day variation was seen.
Table 1 Human sera studied and results of the immunochromatographic test kit using somatic antigen extracted from Strongyloides stercoralis larvae

\begin{tabular}{lll}
\hline No. & Type of sera & Number of positive/total number \\
\hline 1 & Proven strongyloidiasis & $56 / 60$ \\
2 & Healthy controls & $0 / 30$ \\
3 & Opisthorchiasis & $0 / 5$ \\
4 & Hookworm infections & $1 / 5$ \\
5 & Ascariasis & $0 / 5$ \\
6 & Taeniasis & $2 / 5$ \\
7 & Trichuriasis & $2 / 5$ \\
8 & Trichinellosis & $0 / 5$ \\
9 & Giardiasis & $1 / 5$ \\
10 & Amoebiasis & $1 / 5$ \\
11 & Blastocystosis & $1 / 5$ \\
12 & Cysticercosis & $0 / 5$ \\
13 & Angiostrongyliasis & $2 / 5$ \\
14 & Gnathostomiasis & $1 / 5$ \\
15 & Sparganosis & $2 / 4$ \\
16 & Capillariasis & $2 / 5$ \\
17 & Fascioliasis & $2 / 5$ \\
& Sensitivity (\%) & 93.3 \\
& Specificity (\%) & 83.7 \\
& Positive predictive values $(\%)$ & 76.7 \\
& Negative predictive values $(\%)$ & 95.6 \\
\hline
\end{tabular}


The study protocol was approved by the Khon Kaen University Ethics Committee for Human Research (HE611507).

\section{Immunochromatographic test kit}

The rapid ICT kit (named "strongyloidiasis ICT kit") was optimized using somatic antigen extracted from larvae of S. stercoralis. Schematic diagram of ICT kit production was shown (Fig. 1). The test strip itself was based from a nitrocellulose membrane (Sartorius Stedim Biotech SA, Goettingen, Germany). Goat IgG anti-mouse IgG (Lampire Biological Laboratories) $(0.1 \mu \mathrm{L} / \mathrm{mm})$ was sprayed using XYZ3210 Dispense Platform (BioDot, Irvine, CA) onto the membrane to form the control line ("C" in Fig. 2a). Similarly, S. stercoralis antigen $(1 \mathrm{mg} / \mathrm{mL})$ was sprayed as the test line at a flow rate of $0.1 \mu \mathrm{L} / \mathrm{mm}$ ("T" in Fig. 2a), and colloidal gold-conjugated mouse monoclonal anti-human IgG (Kestrel BioSciences Co., Pathumthani, Thailand) was sprayed onto a piece of glass microfiber filter GF33 (Whatman Schleicher \& Schuell, Dassel, Germany) to form the conjugate pad (Fig. . 1). Also required are sample buffer for diluting serum and chromatography buffer. The diagnostic procedure is as follows: dilute the serum samples with sample buffer in the ratio 1:50 and spot an aliquot $(5 \mu \mathrm{L})$ where indicated by the letter $\mathrm{S}$, and add $100 \mu \mathrm{L}$ of chromatography buffer at B (Fig. 2a). A red band should always appear at the $\mathrm{C}$ line (Fig. 2a) to show that the kit is functional. If positive, a red band appears at the $\mathrm{T}$ line within $15 \mathrm{~min}$ (Fig. 2a). The intensity of any positive band was estimated visually (unaided) according to the reference card (Fig. 2b). The minimum cutoff level is 0.5 . The diagnostic parameters of sensitivity, specificity, and positive and negative predictive values were calculated [30].

\section{Results}

The strongyloidiasis ICT kit was evaluated using sera from strongyloidiasis patients, healthy controls, and patients with other parasitic diseases (Table 1 and Fig. 3). Fifty-six serum samples (56/60) from the confirmed strongyloidiasis patients yielded positive results using a cutoff value of 0.5 . In contrast, none of the 30 healthy control sera showed positive results. Some cross-reactivity was observed in serum samples of hookworm infections ( 1 of 5 ), taeniasis ( 2 of 5 ), trichuriasis ( 2 of 5), giardiasis ( 1 of 5), amoebiasis ( 1 of 5), blastocystosis (1 of 5), angiostrongyliasis ( 2 of 5), gnathostomiasis ( 1 of 5 ), sparganosis ( 2 of 4), capillariasis ( 2 of 5), and fascioliasis ( 2 of 5 ). When using 0.5 or above as the cutoff level, the diagnostic sensitivity, specificity, and positive and negative predictive values in ICT were $93.3 \%, 83.7 \%, 76.7 \%$, and $95.6 \%$, respectively.

\section{Discussion}

Point-of-care tests offer considerable advantages for the treatment and control of infectious diseases, including parasitosis [31]. To date, there is still no ICT, the POC test, to detect antibodies for diagnosis of human strongyloidiasis. Here, we developed an ICT using $S$. stercoralis larval extract as the antigen for detection of IgG antibodies. The ICT is rapid, simple to perform, and requires no special equipment or skilled personnel for serodiagnosis of human strongyloidiasis.

We did note some cross-reactions with sera from patients with other parasitoses (Table 1). This is not likely to be a real problem in a clinical setting because the clinical presentation of each of these parasitoses differs from those of strongyloidiasis. We should also note that some patients in group iii (those with other parasitoses) may in fact have had asymptomatic strongyloidiasis: these sera were collected in a strongyloidiasis-endemic area in northeast Thailand. The diagnostic efficacy of our test needs to be evaluated further, using samples from countries where $S$. stercoralis is not endemic. Another note should be considered for ICT sensitivity is some strongyloidiasis sera that found S. stercoralis by the agar-plate culture method were found negative by ICT (Table 1). This reason be possible due to these serum samples were collected in acute phrase of strongyloidiasis and resulting in low antibody response.

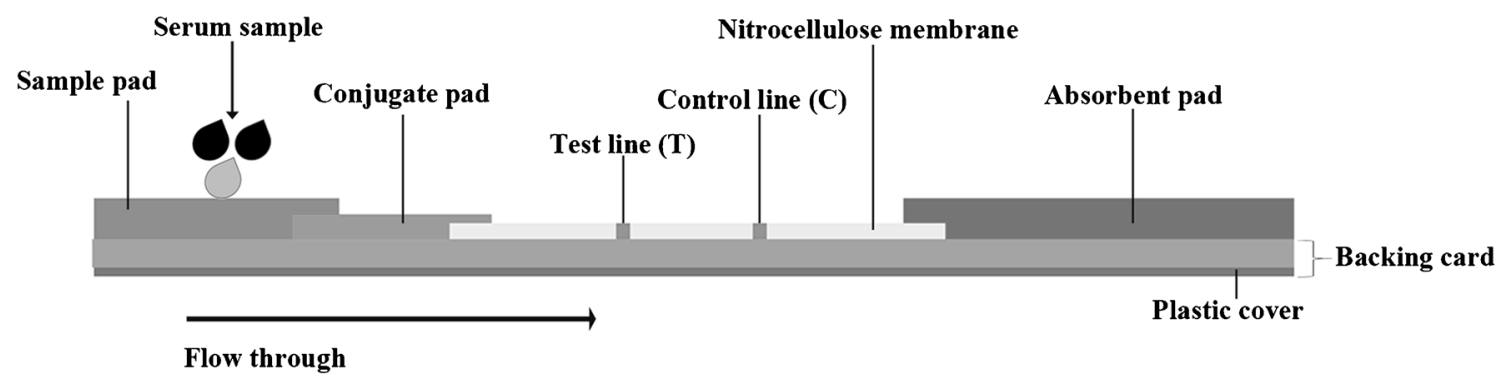

Fig. 1 Schematic diagram of the immunochromatographic strip. The sample pad, conjugate pad, immobilized nitrocellulose membrane, and absorbent pad were stuck together on a plastic backing card. At the test line (T), the Stercoralis stercoralis antigen $(1 \mathrm{mg} / \mathrm{mL})$ and control line (C), the anti mouse $\mathrm{IgG}$ were fixed on the nitrocellulose membrane 
Fig. 2 The

immunochromatographic device for diagnosis of strongyloidiasis. a Example of a positive result on the ICT strip (left) and negative result (right). b The interpretation card for determining the cutoff level

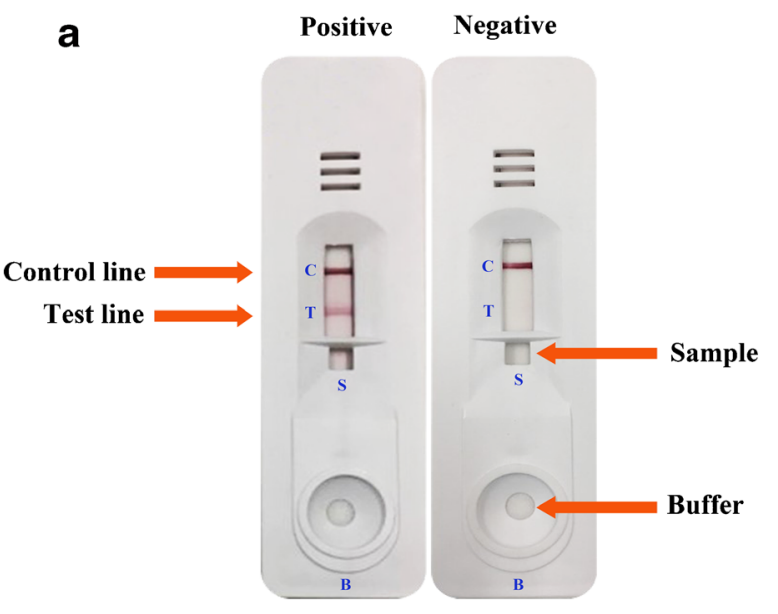

In general, confirmation of strongyloidiasis in chronic carriers is laborious because they usually have a low parasite burden and larvae are released only intermittently in stool [1]. Such asymptomatic carriers can unexpectedly experience dangerous hyperinfection if they become immunocompromised for any reason. Fatal systemic strongyloidiasis can occur in immunosuppressed patients (i.e., patients who receive systemic steroids or cytotoxic treatments (e.g., treatment with anti-neoplastic agents)) [32]. Patients from endemic areas and travelers, who have returned from such areas, should be examined for strongyloidiasis before being given immunosuppressive treatment $[33,34]$. Our ICT can be used as the POC test for screening of such patients, and appropriate anti- helminthic drugs are prescribed for positive cases. A further use for our ICT device is to assess cure in clinical care: the ICT antibody reaction should decrease in level through time posttreatment.

In conclusion, we have developed a diagnostic tool that is fast, simple to use, and can supplement stool examination for clinical diagnosis of strongyloidiasis. It can be used at the local level in resource-poor settings (middle- and low- income countries). The method is important for screening asymptomatic-infected individuals and populations who are "at risk" of developing hyperinfection syndrome or disseminated strongyloidiasis if they are given immunosuppressive treatment for other conditions.

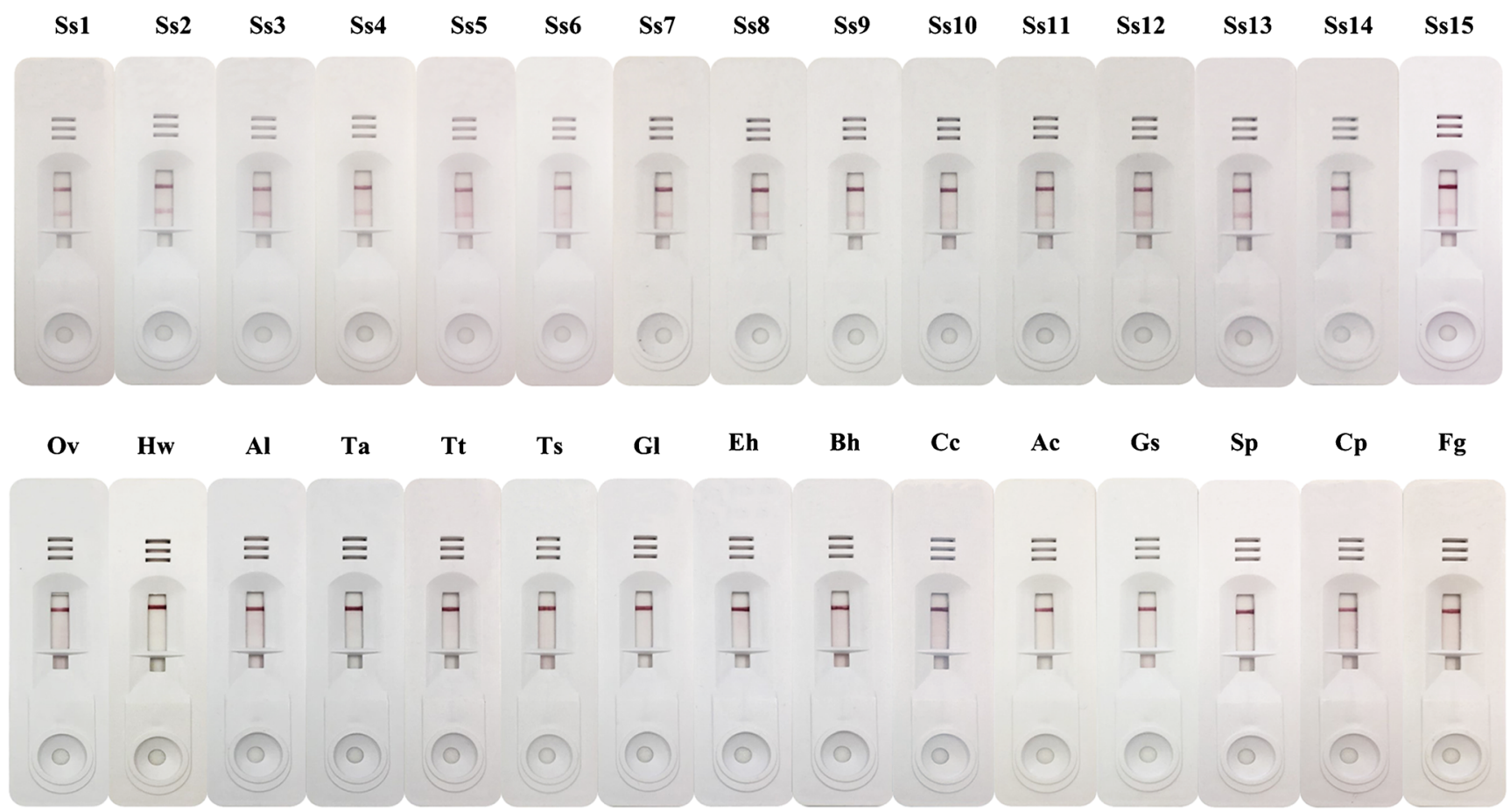

Fig. 3 Representative results in ICT kit. Ss1-Ss15, strongyloidiasis; Ov, opisthorchiasis; Hw, hookworm infection; Al, ascariasis; Ta, taeniasis; Tt, trichuriasis; Ts, trichinellosis; Gl, giardiasis; Eh, amoebiasis; Bh, blastocystosis; Cc, cysticercosis; Ac, angiostrongyliasis; Gs, gnathostomiasis; $\mathrm{Sp}$, sparganosis; $\mathrm{Cp}$, capillariasis; $\mathrm{Fg}$, fascioliasis 
Acknowledgments We would like to thank David Blair for valuable suggestions and assistance with the presentation of this paper through Khon Kaen University Publication Clinic. We also extend our gratitude to Jiraporn Harasan from the Mekong Health Science Research Institute for providing such an effective immunochromatographic technique.

Author contributions All authors contributed to the study conception and design. Material preparation, data collection, methodology, investigation, and analysis were performed by [Lakkhana Sadaow], [Oranuch Sanpool], [Rutchanee Rodpai], [Patcharaporn Boonroumkaew], [Wanchai Maleewong], and [Pewpan M. Intapan]. The first draft of the manuscript was written by [Pewpan M. Intapan] and all authors commented on previous versions of the manuscript. All authors read and approved the final manuscript.

Funding information This study was supported by Distinguished Research Professor Grant, Thailand Research Fund (grant no. DPG6280002) and Khon Kaen University (Pewpan Maleewong Intapan and Wanchai Maleewong); a Scholarship under Doctoral Training Program from Graduate School and Research Affairs, Khon Kaen University (Lakkhana Sadaow, grant number 60164).

\section{Compliance with ethical standards}

Conflict of interest The authors declare that they have no conflicts of interest.

Ethical approval All procedures performed in studies involving human participants were in accordance with ethical standards of the Khon Kaen University Ethics Committee for Human Research (HE611507) and with the 1964 Helsinki declaration and its later amendments or comparable ethical standards.

Open Access This article is distributed under the terms of the Creative Commons Attribution 4.0 International License (http:// creativecommons.org/licenses/by/4.0/), which permits unrestricted use, distribution, and reproduction in any medium, provided you give appropriate credit to the original author(s) and the source, provide a link to the Creative Commons license, and indicate if changes were made.

\section{References}

1. Siddiqui AA, Berk SL (2001) Diagnosis of Strongyloides stercoralis infection. Clin Infect Dis 33:1040-1047

2. Bethony J, Brooker S, Albonico M, Geiger SM, Loukas A, Diemert D, Hotez PJ (2006) Soil-transmitted helminth infections: ascariasis, trichuriasis, and hookworm. Lancet 367:1521-1532

3. Casavechia MT, Lonardoni MV, Venazzi EA, Campanerut-Sá PA, da Costa Benalia HR, Mattiello MF, Menechini PV, Dos Santos CA, Teixeira JJ (2016) Prevalence and predictors associated with intestinal infections by protozoa and helminths in southern Brazil. Parasitol Res 115:2321-2329

4. Olsen A, van Lieshout L, Marti H, Polderman T, Polman K, Steinmann P, Stothard R, Thybo S, Verweij JJ, Magnussen P (2009) Strongyloidiasis- the most neglected of the neglected tropical diseases? Trans R Soc Trop Med Hyg 103:967-972

5. Thanchomnang T, Intapan PM, Sanpool O, Rodpai R, Tourtip S, Yahom S, Kullawat J, Radomyos P, Thammasiri C, Maleewong W (2017) First molecular identification and genetic diversity of Strongyloides stercoralis and Strongyloides fuelleborni in human communities having contact with long-tailed macaques in Thailand. Parasitol Res 116:1917-1923

6. Valerio L, Roure S, Fernández-Rivas G, Basile L, Martínez-Cuevas O, Ballesteros ÁL, Ramos X, Sabrià M, North Metropolitan Working Group on Imported Diseases (2013) Strongyloides stercoralis, the hidden worm. Epidemiological and clinical characteristics of 70 cases diagnosed in the north metropolitan area of Barcelona, Spain, 2003-2012. Trans R Soc Trop Med Hyg 107: 465-470

7. Buonfrate D, Formenti F, Perandin F, Bisoffi Z (2015) Novel approaches to the diagnosis of Strongyloides stercoralis infection. Clin Microbiol Infect 21:543-552

8. Nutman TB (2017) Human infection with Strongyloides stercoralis and other related Strongyloides species. Parasitology 144:263-273

9. Verweij JJ, Canales M, Polman K, Ziem J, Brienen EA, Polderman AM, van Lieshout L (2009) Molecular diagnosis of Strongyloides stercoralis in faecal samples using real-time PCR. Trans R Soc Trop Med Hyg 103:342-346

10. Janwan P, Intapan PM, Thanchomnang T, Lulitanond V, Anamnart W, Maleewong W (2011) Rapid detection of Opisthorchis viverrini and Strongyloides stercoralis in human fecal samples using a duplex real-time PCR and melting curve analysis. Parasitol Res 109: 1593-1601

11. Repetto SA, Alba Soto CD, Cazorla SI, Tayeldin ML, Cuello S, Lasala MB, Tekiel VS, González Cappa SM (2013) An improved DNA isolation technique for PCR detection of Strongyloides stercoralis in stool samples. Acta Trop 126:110-114

12. Schär F, Odermatt P, Khieu V, Panning M, Duong S, Muth S, Marti H, Kramme S (2013) Evaluation of real-time PCR for Strongyloides stercoralis and hookworm as diagnostic tool in asymptomatic schoolchildren in Cambodia. Acta Trop 126:89-92

13. Kristanti H, Meyanti F, Wijayanti MA, Mahendradhata Y, Polman K, Chappuis F, Utzinger J, Becker SL, Murhandarwati EEH (2018) Diagnostic comparison of Baermann funnel, Koga agar plate culture and polymerase chain reaction for detection of human Strongyloides stercoralis infection in Maluku, Indonesia. Parasitol Res 117:3229-3235

14. Formenti F, La Marca G, Perandin F, Pajola B, Romano M, Santucci B, Silva R, Giorli G, Bisoffi Z, Buonfrate D (2019) A diagnostic study comparing conventional and real-time PCR for Strongyloides stercoralis on urine and on faecal samples. Acta Trop 190:284-287

15. Sykes AM, McCarthy JS (2011) A coproantigen diagnostic test for Strongyloides infection. PLoS Negl Trop Dis 5:e955

16. Levenhagen MA, Costa-Cruz JM (2014) Update on immunologic and molecular diagnosis of human strongyloidiasis. Acta Trop 135: 33-43

17. Eamudomkarn C, Sithithaworn P, Sithithaworn J, Kaewkes S, Sripa B, Itoh M (2015) Comparative evaluation of Strongyloides ratti and $S$. stercoralis larval antigen for diagnosis of strongyloidiasis in an endemic area of opisthorchiasis. Parasitol Res 114:2543-2551

18. Northern C, Grove DI (1990) Strongyloides stercoralis: antigenic analysis of infective larvae and adult worms. Int J Parasitol 20:381387

19. Sato Y, Inoue F, Matsuyama R, Shiroma Y (1990) Immunoblot analysis of antibodies in human strongyloidiasis. Trans R Soc Trop Med Hyg 84:403-406

20. Conway DJ, Bailey JW, Lindo JF, Robinson RD, Bundy DA, Bianco AE (1993) Serum IgG reactivity with 41-, 31-, and 28$\mathrm{kDa}$ larval proteins of Strongyloides stercoralis in individuals with strongyloidiasis. J Infect Dis 168:784-787

21. Conway DJ, Lindo JF, Robinson RD, Bundy DA, Bianco AE (1994) Strongyloides stercoralis: characterization of immunodiagnostic larval antigens. Exp Parasitol 79:99-105 
22. Atkins NS, Conway DJ, Lindo JF, Bailey JW, Bundy DA (1999) L3 antigen-specific antibody isotype responses in human strongyloidiasis: correlations with larval output. Parasite Immunol 21:517-526

23. Sudre AP, Siqueira RC, Barreto MG, Peralta RH, Macedo HW, Peralta JM (2007) Identification of a $26-\mathrm{kDa}$ protein fraction as an important antigen for application in the immunodiagnosis of strongyloidiasis. Parasitol Res 101:1117-1123

24. Rodpai R, Intapan PM, Thanchomnang T, Sanpool O, Janwan P, Laummaunwai P, Wongkham C, Insawang T, Maleewong W (2016) Strongyloides stercoralis diagnostic polypeptides for human strongyloidiasis and their proteomic analysis. Parasitol Res 115: 4007-4012

25. Yunus MH, Arifin N, Balachandra D, Anuar NS, Noordin R (2019) Lateral flow dipstick test for serodiagnosis of strongyloidiasis. Am J Trop Med Hyg 101:432-435. https://doi.org/10.4269/ajtmh.190053

26. Harada Y, Mori O (1955) A new method for culturing hookworm. Yonago Acta Med 1:177-179

27. Elkins DB, Haswell-Elkins M, Anderson RM (1986) The epidemiology and control of intestinal helminths in the Pulicat Lake region of Southern India. I. Study design and pre- and post-treatment observations on Ascaris lumbricoides infection. Trans R Soc Trop Med Hyg 80:774-792

28. Koga K, Kasuya S, Khamboonruang C, Sukhavat K, Ieda M, Takatsuka N, Kita K, Ohtomo H (1991) A modified agar plate method for detection of Strongyloides stercoralis. Am J Trop Med Hyg 45:518-521

29. Intapan PM, Khotsri P, Kanpittaya J, Chotmongkol V, Maleewong W, Morakote N (2008) Evaluation of IgG4 and total IgG antibodies against cysticerci and peptide antigens for the diagnosis of human neurocysticercosis by ELISA. Asian Pac J Allergy Immunol 26: 237-244

30. Galen RS (1980) Predictive value and efficiency of laboratory testing. Pediatr Clin N Am 27:861-869

31. Clerc O, Greub G (2010) Routine use of point-of-care tests: usefulness and application in clinical microbiology. Clin Microbiol Infect 16:1054-1061

32. Krolewiecki A, Nutman TB (2019) Strongyloidiasis: a neglected tropical disease. Infect Dis Clin N Am 33:135-151

33. Hagelskjaer LH (1994) A fatal case of systemic strongyloidiasis and review of the literature. Eur J Clin Microbiol Infect Dis 13: 1069-1074

34. Byard RW (2019) Lethal strongyloidiasis-diagnostic and forensic issues. J Forensic Legal Med 62:103-106

Publisher's note Springer Nature remains neutral with regard to jurisdictional claims in published maps and institutional affiliations. 